\title{
EDUCATIONAL STRUCTURE AND EMPLOYMENT OF POPULATION IN BULGARIA - GENERAL AND REGIONAL ISSUES
}

DOI: http://dx.doi.org/10.18509/GBP.2016.42

UDC: 377.3(497.2)

\author{
Assoc. Prof. Dr. Toni Traykov \\ Assoc. Prof. Dr. Kliment Naydenov \\ Sofia University "St. Kliment Ohridski” - Bulgaria
}

\begin{abstract}
The importance of education and the educational structure of the population to overall socio-economic development has set their inclusion as structure-item in the Human Development Index used in the United Nations Development Programme. Quality education is one of the main prerequisites for the development of each society. Amid general negative quantitative and qualitative changes in our population keeps some positive trends relating to its educational level. Raising the education of the population of Bulgaria in XX century remains a trend at the beginning of the present century.
\end{abstract}

Keywords: vocational education, labor market, workforce, illiterates

\section{INTRODUCTION}

Quality education is one of the main prerequisites for the development of each society. Over the last decade, however Bulgarian government did not put the necessary focusing on its development and many units remained in school education unreformed and kept its kind since the end of the socialist period. The level of education is crucial to the successful implementation of population in the labor market. The availability of education and training for certain work activities contribute to personal fulfillment and provide a higher standard and quality of life. Increasing the educational level of the people is an opportunity for the optimal exploitation of the workforce and for more active involvement in society of marginalized segments of the population. The importance of education and the educational structure of the population to overall socio-economic development has set their inclusion as structure-item in the Human Development Index used in the United Nations Development Programme. According to the methodology, adopted by the National Statistical Institute of Bulgaria, education statistically evaluated by the structure of the adult population (or separate contingents of it) as the highest level of education. Changes in educational status is monitored carried out over a period censuses. The education structure includes the population of 7 years and above.

Amid general negative quantitative and qualitative changes in our population keeps some positive trends relating to its educational level. Raising the education of the population of Bulgaria in XX century remains a trend at the beginning of the present century. Data from the last census in 2011 showed an increase in the relative share of persons with higher and secondary education of the population of 7 years and above. Compared with the previous census (2001) the increase in graduates it's from $14.1 \%$ to $19.6 \%$, while those with secondary education - from $37.9 \%$ to $43.4 \%$.

Meanwhile, has a significant reduction in the share of persons with completed primary and primary education. Between the last two censuses, the mentioned decrease is from 
$39.9 \%$ to $30.9 \%$. It should be noted that achieving higher levels of education in recent decades is mainly due to the increase in the education of the population in younger age groups. This feature combined with a change in immigration attitudes of young people can have a positive impact on the general state of the labor market in Bulgaria. Reducing the emigration of young people with secondary and higher education is possible only when creating greater opportunities for their implementation and refinement of the requirements for professional expertise and experience. Positive attitudes in this direction create changes in the so-called youth unemployment. According to Eurostat youth unemployment in Bulgaria decreased from 28\% in 2012 to $20 \%$ in 2015. This is associated with measures for youth employment and moderate economic growth recorded in 2015. The successful management of the European Social Fund also has a positive influence. According to the European Commission by October 2015 Bulgaria in the absorption of funds under projects financed by this fund is $94 \%$ - with an average of $87 \%$ for the EU.

Vocational education can directly connect knowledge and skills of young people to the needs of the labor market. Vocational education is still less attractive to people than ordinary secondary education, despite its proven efficiency of the labor market. People with acquired professional qualification represent $37 \%$ of the workforce in Bulgaria and are nearly twice more than those with only secondary education. Although interest in mainstream schools is higher and vocational education suffers from a number of imperfections vocational training graduates realize better labor market to the total realization of high school graduates.

Table 1. Wokrforce by level of education, 2014

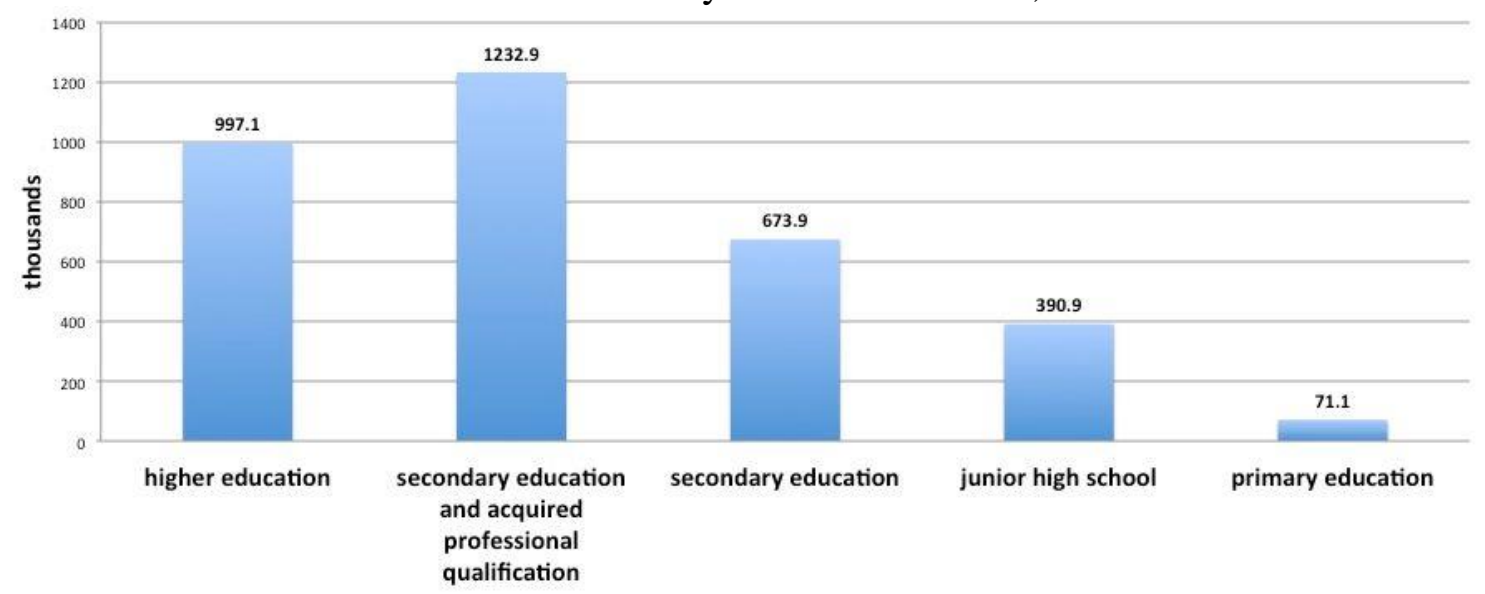

Labor market workforce with acquired professional qualifications of indicators which it is ranked at the highest level then those with a secondary education and after these with higher education. Workforce with professional qualifications is occupied mainly in industry, where is the highest labor productivity. 
Table 2. Employment and unemployment rate and education level of population 15+

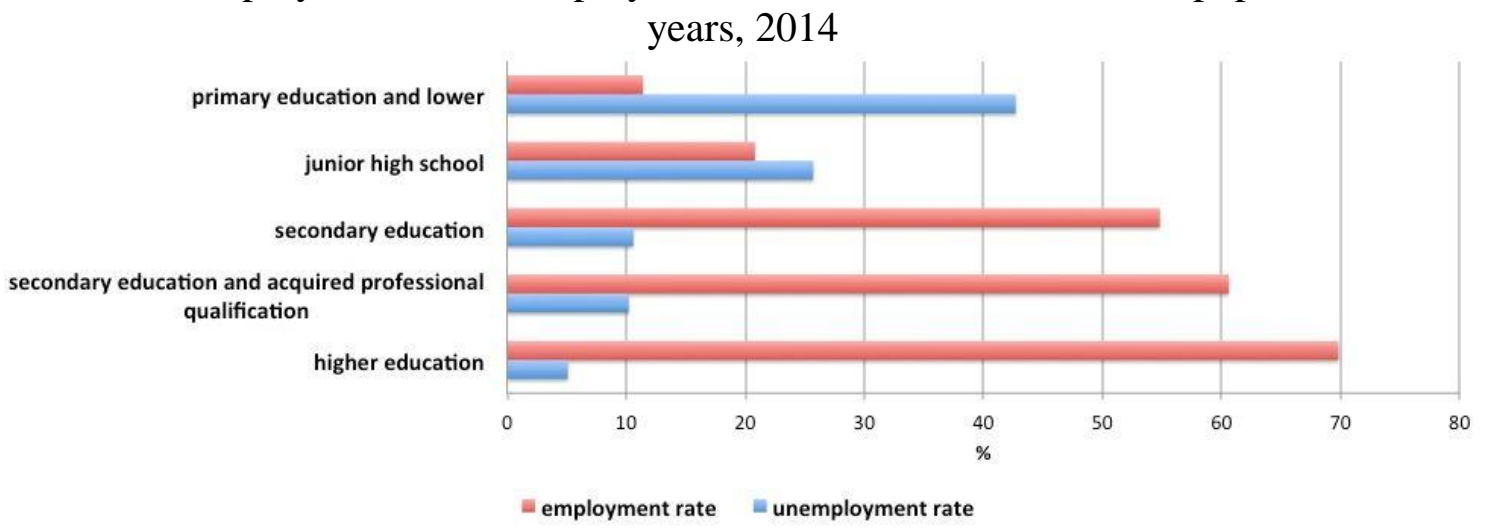

The optimal use of available human resources in our country requires a full account of the differences in the levels of education of the population by place of residence, gender, ethnicity or other structural characteristics. Notwithstanding the overall positive changes in the educational structure of the population in Bulgaria, there are a number of problems. They are related to differences in the educational attainment of different groups and strata of the population. For example, there are significant differences in the educational structure of the population in towns and villages. The persons graduated higher and secondary education among urban populations represent $71.6 \%$, while the rural population with such education is only $40.3 \%$. Maintaining a significantly lower educational level of rural population is a result of its stronger aging, and the emigration of young people with higher education to cities. There they find greater opportunities for professional development. The proportion of graduates in rural areas is only $5.8 \%$ and that creates problems in finding qualified specialists for agriculture and forestry, education, health and social activities. Similar problems are typical for smaller populous cities and even some regional centers such as Smolyan, Kardzhali, Targovishte, Silistra and others.

In the analysis of the changes in the educational structure of the population it is necessary to note the differences in individual age groups. In comparison, the proportion of graduates people aged 20-39 is $25.6 \%$, while the population of 65 and above it has decreased to $15.3 \%$. Meanwhile graduates only primary education in the population of over working age was $12.4 \%$ versus $3.8 \%$ in 20-39 year age group. As the most problematic in terms of aging and lack of qualified staff of working age are the regions and municipalities in northwestern Bulgaria, The Balkan Mountains, Strandzha-Sakar and border areas of West Bulgaria. The last census data show relatively similar values in terms of overall education of men and women. For example, the share of men with secondary and higher education is $63.6 \%$, while for women it was $62.4 \%$. However, there are significant differences in different ethnic groups. $70.3 \%$ of persons of Bulgarian ethnic group are higher and secondary education. Meanwhile, persons of Turkish ethnic group with such educational level are only $30.0 \%$, of which the share of graduates is only $4.1 \%$. Values in the Roma ethnic group are even lower - only $0.3 \%$ of the people in this group have higher education. The differences in education levels and determine differences in employment among the three largest ethnic groups in Bulgaria. The highest employment has Bulgarians (between 80 and 90\%). They are followed by Turkish ethnicity (70-80\%) and Roma (60-65\%). The existing distribution level of education 
determines a significantly smaller number of qualified specialists among Turkish and Roma population and this is an obstacle for their active involvement in society.

The existence of a compact communities among Turkish and Roma ethnic group in some districts and municipalities in the country is the main reason for more expressive differences in education levels between male and female population. Influence in this direction have traditionally lower female education by Roma and Turkish ethnic group. Certain influence for that have traditional lifestyle, a large number of children in the family and their cultivation activities. In the Turkish ethnic group Bulgarians Muslims influenced by higher employment of the population including women in agricultural labor. And now more than half of the Turkish population in the country still lives in the villages. Typical examples in this regard are some of the municipalities in the Eastern Balkan Mountains, Ludogorie, Eastern Rhodopes and others parts of the country. There are differences in the literacy score or the ability of people to read and write in separate population groups. The data of the last census showed $1.7 \%$ share of the illiterate population of 9 and above. And in this case remain differences among the representatives of both sexes. In women, the proportion of illiterates is $2.0 \%$ and for men $1.3 \%$. The differences in favor of the male population are more pronounced in regions with mixed ethno-confessional structure where the total proportion of illiterates is higher than the national average. As examples can be mentioned Kardzhali, Razgrad, Targovishte and others. A higher proportion of illiterate have among the elderly in retirement. This is the reason in the aforementioned areas with strong aging population to observe and higher share illiterate.

The realization of experts with different educational degrees depends on the demand and supply of labor. After the beginning of the economic crisis in 2009, the National Statistical Institute of Bulgaria reported an increase in the economic development of the country in late 2015. According to analysts, the reasons for positive change are certain external and internal factors. Among the external factors are the changes in the international situation. Such changes are the processes of recovery of the European economy, the change in the exchange rate euro-dollar and significant falls in fuel prices on the international market. An important internal factor in Bulgaria is better absorption in recent times of EU funds. This and the increasing investment in some sectors of the economy, has contributing to employment growth and recovery in the labor market. Reducing unemployment in 2015 led to increased consumer confidence and lead to an increase in individual consumption. According to the Institute for Market Economics the main reason for the increase in consumption has the growth of public spending at the end of 2015 compared to the previous year. One cause of this is the timely disbursement of European projects at the end of last year due to the completion of the deadline for payments under the previous programming period (2007-2013.).

Economic recovery after the crisis in 2009-2013, led to improvement in the labor market in the country in general and the separate regions. Best indicators have regions with better availability of skilled labor - a prerequisite for attracting more investment. According to a research the Institute for Market Economics in 2015 the improvement of the labor market is a fact for over than half of the districts in the country. Sofia (capital) remains the only area ahead of many others 27 districts. Besides Sofia (district) employment grew more noticeable in Plovdiv, Blagoevgrad, Burgas and Pazardzhik. Notwithstanding the overall positive trends still remain differences in the state of the labor market in Northern and Southern Bulgaria. As an exception to the general decline in North Bulgaria are the good results reported in regional centers Varna and Veliko Tarnovo. As a result of 
positive developments in the labor market, the number of employed in Varna exceeded 200000 people. Contribution to this growth is reported in the traditional town industries, including tourism. Activities related to tourism are crucial for the rising employment in Veliko Tarnovo. In comparison, the number of employees in the city has reached and even surpassed the number of employees in Rousse. The main factor for the economic recovery and improving employment is foreign investment. The latter are typical of major regional centers in Southern Bulgaria - Burgas, Sofia, Plovdiv, Stara Zagora and Pazardzhik. At the other extreme are the areas with a strong worsening of demographic situation - Vidin, Vratsa, Montana, Kyustendil, Lovech, Pernik and others. Declining population, including the working age, makes their territory unattractive for long-term investment and leading to maintain lower than the national average employment. An exception is the Lovech region. In some municipalities in its territory lack of investment is offset by better absorption of funds under various EU programs.

Reducing disparities in economic development of the different regions of Bulgaria requires a comprehensive strategy based on the principles of cohesion policy. Investments should be oriented and to the less developed regions and municipalities in order to avoid their backlog. One of the possible measures in this direction is the implementation of decentralization. With its use possible part of direct taxes to be collected and managed by local authorities, but it must function in the current levels, without additional charges. This would provide more funds for the needs of municipalities, including the implementation of programs of economic and social purpose.

\section{REFERENCES}

[1] Census of Population and Housing in 2011. Demographic and social characteristics of the population. Sofia, Bulgaria 2011.

[2] Education in Bulgaria. Edition NSI, Sofia, Bulgaria 2004.

[3] Regional Profiles: development indicators 2015. IV edition of Institute for Market Economics

[4] The population of Bulgaria at the beginning of the XXI century. Status and Trends. Bulgarian Academy of Sciences, Sofia, Bulgaria 2011. 